\title{
Os papéis sociais da infância e suas influências na moda por meio da revista Vogue Bambini
}

The social roles of childhood and its influences in fashion through Vogue Bambini magazine 
artigo ]

\section{[CLAUDIA SCHEMES]}

Doutora e mestra em História, professora do PPG em Processos e Manifestações

Culturais - Universidade Feevale/RS.

\section{E-mail: claudias@feevale.br}

\section{[JULIA CRISTINA VALIM BERNHARD]}

Mestre em Processos e Manifestações Culturais, bacharel em Design de Moda Universidade Feevale/RS.

\section{E-mail: juliabernhard@gmail.com}

[resumo] Este artigo tem como objetivo examinar a relação entre as representações da infância e as suas influências na moda do século XXI por meio da abordagem das propagandas veiculadas nos periódicos direcionados às mulheres, especificamente na revista italiana Vogue Bambini, dos anos 2002 e 2008.

Por meio da análise semiótica de anúncios publicitários, percebemos que os papéis sociais da infância nem sempre são condizentes com a moda proposta para as crianças e que, mesmo com o conhecimento das suas necessidades, muitas vezes, 0 mercado não Ihes assegura roupas com requisitos indispensáveis, como conforto e liberdade.

\section{[palavras-chave]}

infância; moda; publicidade; Vogue Bambini.

[abstract] This article aims to examine the relationships between childhood representations and their influences in the 21st century fashion through the approach of the advertisements in the periodical directed to women, specifically in the Italian magazine Vogue Bambini, from 2002 and 2008. Through the semiotic analysis of advertisements for children's fashion, we realize that the social roles of childhood are not always consistent with the fashion proposed for children and that, even with the knowledge of their needs, the market often does not guarantee clothing with indispensable requirements, such as comfort and freedom.

[keywords] childhood; fashion; publicity; Vogue Bambini. 


\section{Introdução}

Os estudos em moda são cada vez mais frequentes, sendo esse tema aliado às mais diversas áreas das ciências humanas, como sociologia, antropologia, filosofia, comunicação, semiótica, história e psicologia. Tão estudado quanto a moda é a infância, tratada tanto como constructo social quanto como desenvolvimento biológico, ao passo que é crescente o estudo sobre os temas em separado. São dificilmente encontradas publicações que os associam, ainda mais quando se fala especificamente de moda infantil. Os obstáculos para estudar a moda infantil se dão, principalmente, nos séculos anteriores ao XVII, quando as crianças são muito pouco relatadas em obras de história da moda. De acordo com Marshall (2008), a escassez nos registros sobre as crianças, especificamente falando em relação à história da moda, se dá pelas parecenças inevitáveis entre roupas infantis e adultas.

Da mesma forma que observamos a dificuldade de pesquisar sobre a indumentária infantil nos séculos passados, o século XX também não traz muitos registros sobre a moda para esse público. Isso pode ser explicado pelo fato de esse século ser relacionado com a era dos estilistas, constatando-se em pesquisas bibliográficas a ênfase à produção ligada ao nome do profissional de determinada década. A moda é muito mais direcionada ao público adulto do que ao infantil, já que quando se fala em crianças, mesmo em livros em que são contempladas, elas desaparecem ou passam a ser tratadas de forma ainda mais sucinta com a chegada do século XX. 0 século XXI, todavia, tem seu acesso facilitado por meio de revistas e da internet, que vêm servindo como banco de dados para a moda, com espaço cada vez mais direcionado para as crianças'.

As vestes infantis e sua semelhança em relação às roupas propostas para os adultos, na atualidade e no passado, levantam questionamentos sobre 0 porquê da aproximação e do distanciamento entre idades tão diferentes e a indumentária. A ideia de que as crianças devem viver a infância com liberdade e fantasia e que as roupas fazem parte dos artefatos que possibilitam a plenitude do desenvolvimento nessa etapa da vida são fatores propulsores para 0 estudo da moda infantil.

De acordo com o tratamento dado aos infantes e sua representação social, desde a inexistência da noção de infância até a atualidade, ocorreram processos que os aproximaram ou os diferenciaram da idade adulta, proporcionando ou restringindo a liberdade de movimento, de conforto e de fantasia. 
A roupa e a indumentária podem ser consideradas essenciais como objetos de análise, uma vez que, com elas, os aspectos que possibilitam o reconhecimento do indivíduo e seu pertencimento a determinado grupo da sociedade tornam-se passiveis de identificação. Entre esses aspectos estão os temporais, os econômicos, os tecnológicos, os geográficos e os corporais. Eles resultam na identificação do periodo de utilização da veste, na definição da classe econômica e também nas formas e nas transformações pelas quais o corpo é submetido. Isso é possivel com o estudo das caracteristicas da indumentária, entre elas, as técnicas de confecção, os materiais empregados (tecidos e aviamentos), os beneficiamentos (tingimentos, estampas e lavagens), as cores, as estampas, o design e a modelagem.

Embora haja aspectos que possibilitam o estudo aprofundado das vestes atualmente, a moda infantil de séculos passados é vista de forma bastante simplificada, ou seja, ela é quase sempre considerada cópia fiel das roupas dos adultos. De acordo com Noreen Marshall (2008), essa simplificação ocorre porque, na atualidade, a maioria das pessoas que trabalha na área da moda não tem conhecimento histórico suficiente e está inserida em uma cultura que não consegue enxergar as diferenças entre adultos e crianças.

Tendo em vista que a moda infantil varia com o passar do tempo, por que motivo as vestes são criadas por vezes em prol da liberdade de movimento e do lúdico e em outros periodos assemelham-se a cópias reduzidas das roupas adultas? Será que essas transições, que oscilam entre os extremos do conforto e desconforto, têm ligação com o desenvolvimento do significado de infância e com os papéis sociais vividos pelas crianças? E na atualidade, como se caracteriza a moda infantil? Quais as relações entre as representações sociais das crianças ocidentais e a moda/indumentária proposta para elas no desenvolvimento do conceito de infância? Esses são alguns questionamentos que embasam este artigo, cujo objetivo principal é examinar as relações entre as representações de infância e suas influências na moda do século XXI por meio da abordagem das propagandas veiculadas no periódico Vogue Bambini.

Para a análise das imagens representativas do século XXI, são usadas fotografias de campanhas publicitárias relativas ao periodo de outono/inverno e primavera/verão de 2002 e 2008 presentes na revista italiana Vogue Bambini?. Por ser um importante veículo na divulgação da moda, a escolha da revista específica de moda infantil proveniente da Itália se justifica por apresentar campanhas publicitárias internacionais de marcas utilizadas em diferentes partes do mundo. Como não há repetição das marcas em todas as edições escolhidas, são analisadas as imagens que mais representam os dois vieses de tendências propostas neste estudo: 0 da moda miniadulta e o da confortável e alegre. Os anos das edições foram escolhidos de modo a contemplar tendências ao longo do início do século XXI, mostrando as possiveis semelhanças e diferenças da evolução da moda infantil desse periodo. Acreditamos que as tendências indumentárias desses anos apresentam representações de crianças e roupas com aproximações e distanciamentos da moda adulta. 
Entre os anúncios publicados, foram escolhidos os de marcas com representatividade internacional e foco na venda das roupas e descartados os que davam ênfase aos calçados ou acessórios e também os que não mostravam as vestes $e_{1}$ dessa forma, enfatizavam a marca. A idade das crianças nas campanhas publicitárias foram identificadas de forma aproximada, com base em sua aparência nas fotografias.

Svendsen (2010) cita a pintura e a fotografia como recursos visuais dos quais a nossa percepção sobre a moda se fazem dependentes. Para compreender a moda e, nesse caso específico, as possiveis relações entre ela e os papéis sociais da infância, a análise das imagens é fundamental e, de acordo com Martins (2004, p. 23), "a pintura e a fotografia continuam sendo a grande fonte para a apreensão dos estudos de moda: quer como referência histórica, quer como base para criações".

Como apoio metodológico para a análise das imagens, utilizamos a obra de Martine Joly (1996), que tem como objetivo auxiliar na leitura racional e na compreensão. Segundo a autora, a fotografia de moda é uma imagem implicativa e, portanto, conotativa, que navega entre o expressivo, por meio do estilo do fotógrafo, o poético, manifestado pelo trabalho com diversos parâmetros da imagem (iluminação, pose...), e o conotativo, que é a implicação do espectador e eventual futuro comprador (JOLY, 1996).

\section{A história da infância e da indumentária infantil}

A história da indumentária infantil, apresentada brevemente a seguir, é um instrumento importante que nos permite compreender as sociedades em diferentes periodos, pois seus costumes, experiências, valores e crenças são comunicados também pelas roupas.

Segundo Postman (1999), na Grécia Antiga e no Império Romano, ainda não existiam definições para criança, mas foi aí que surgiu a primeira ideia do que viria a ser a infância, pois havia uma preocupação especial para que as crianças frequentassem a escola. Nos tempos medievais, a noção de infância cultivada pelos gregos e romanos desapareceu, mas isso não quer dizer que as crianças eram maltratadas, negligenciadas, abandonadas ou desprezadas pelos adultos. 0 conceito de infância não diz respeito somente à afeição pelas crianças, mas sim a uma consciência das suas necessidades e particularidades. Nesse período, as crianças também estiveram ausentes nos registros de história de vida ou na literatura, elas eram, no máximo, figuras marginais em um mundo adulto (HEYWOOD, 2004).

Essa indiferença pelas caracteristicas próprias da infância até os tempos medievais pode ser observada também na indumentária, pois não havia nenhuma particularidade no traje infantil. A mesma roupa vestia todas as idades, mantendo os degraus da hierarquia social.

No Renascimento, a escolaridade tornou-se diferencial na vida das crianças. Assim, ser criança passou a estar vinculado a saber ler graças à difusão 
da prensa tipográfica. Nesse período, enquanto as crianças eram inseridas no mundo da leitura, também eram introduzidas no mundo adulto e nos assuntos a ele relacionados (POSTMAN, 1999). Um novo sentimento de infância surgia na era moderna, o qual enfatizava que a "criança, por sua ingenuidade, gentileza e graça, tornava-se uma fonte de distração e relaxamento para o adulto, um sentimento que podemos chamar de paparicação" (ARIĖS, 1981, p. 158).

Já, segundo Oliveira (2007, p. 25), nos séculos XVII e XVIII, surge a ideia de que a criança deve ser educada e ter sua moral preservada, ou seja, precisa "receber um tratamento diferenciado em relação aos adultos". Entre os moralistas e educadores da época, outro sentimento em relação às crianças se formava, inspirando toda a educação até o século XX, ou seja, a ideia de que a criança era uma criatura frágil e que precisava, ao mesmo tempo, de cuidados e disciplina.

Essa conduta aos poucos se estabeleceu nas relações familiares. A criança deixou de ser paparicada apenas por distração e brincadeira e passou a ser alvo de interesse psicológico e moral. Era o início de um sentimento sério e autêntico em relação à infância, "não convinha ao adulto se acomodar à leviandade da infância [...] Tentava-se penetrar na mentalidade das crianças para melhor adaptar a seu nivel os métodos da educação" (ibidem, p. 163).

Foi nos primórdios da época iluminista que definitivamente distinguiu-se a infância da fase adulta, conforme as caracteristicas de cada uma delas e a pedagogia que as envolvia. A partir desse período, verificamos algumas pequenas e significativas mudanças no traje infantil. Crianças de boa família, tanto da nobreza quanto da burguesia, já tinham uma roupa reservada à sua idade: usavam vestidos compridos, abertos na frente, fechados por botões ou agulhetas.

Entretanto, "assim que as crianças deixavam os cueiros, ou seja, a faixa de tecido que era enrolada em torno do seu corpo", ela já era vestida de acordo com os homens e mulheres de sua condição social (ibidem, p. 69). Para Ariès (1981), antes dos 4 ou 5 anos era impossivel distinguir, pela roupa, um menino de uma menina. 0 menino, até essa idade, usava vestidos e saias iguais aos das meninas, e esse hábito perdurou por muito tempo.

A concepção de infância, que teve início no século XVII, beneficiou primeiro os meninos, enquanto as meninas persistiram por mais tempo no modo de vida tradicional, pois a separação entre crianças e adultos ainda não existia no caso delas, em nenhuma idade - elas eram sempre vestidas como mulheres adultas. A infância, que aproximava mais as meninas dos adultos do que os meninos, parecia um incentivo da sociedade para que elas se tornassem mulheres mais rapidamente. Com 10 anos, as meninas já eram tratadas como mulheres em miniatura. Essa precocidade pode ser explicada por uma educação que as levava a se comportar desde muito cedo como adultas, pois, além da aprendizagem das tarefas domésticas, elas não recebiam mais nenhuma educação. Mesmo nas famílias em que os meninos iam ao colégio, as meninas não tinham educação formal - elas começaram a frequentar a escola bem mais tarde e lentamente (KERN, 2010). 
Na metade do século XVIII, Jean-Jacques Rousseau apresentou uma nova visão de criança. A infância passou a ser vista como um estado natural e separado, a criança deixou de ser tratada como um miniadulto e começou a ter valor e necessidades próprias (ARIĖS, 1981).

Finalmente, chegamos ao traje especializado da infância que hoje nos é familiar. A partir daí, as etapas do crescimento que transformavam as crianças em homens tornaram-se completamente visiveis por meio das roupas, como uma espécie de rito de passagem que era preciso respeitar.

Esse hábito de diferenciar as roupas infantis das dos adultos revela uma nova preocupação, desconhecida na Idade Média: a de isolar a criança, separá-la por meio da vestimenta, praticamente criando um uniforme infantil. A adoção desse traje específico marca um periodo muito importante para a criação da ideia de infância. Entretanto, segundo Barbosa e Quedes (2007), a humanidade passou de um periodo de conceito de infância praticamente inexistente para a sua extrema exaltação e, hoje, no início do século XXI, tal infância está reduzida.

\section{As contradições da moda infantil do século XXI}

A atualidade é marcada por incessantes avanços tecnológicos e pela informação acessivel a todos os públicos em tempo real. Sendo o acesso à informação associado à revelação dos segredos adultos, de acordo com Postman (1999), a televisão tornou-se a maior divulgadora de assuntos que deveriam ser mantidos em sigilo, entretanto, não só a programação televisiva prejudica o desenvolvimento infantil como a publicidade apresenta outra preocupação dos adultos em relação às crianças ${ }^{3}$.

De modo a diminuir a quantidade e melhorar a qualidade da informação repassada para as crianças por meio da publicidade na televisão, o Instituto Alana promove campanhas que buscam defendê-las dos impactos do consumismo. Essas ações, segundo o instituto, ilustram a preocupação com o acesso à informação desmedida para as crianças que ocorre fortemente por meio da televisão, da internet e de redes sociais de uso destinado a elas. Assim sendo, também ilustram a realidade do século XXI, em que a combinação da tecnologia com o acesso facilitado à informação se faz perfeita para a formação do cenário atual da moda. Múltiplas tendências ${ }^{4}$ em coleções criadas por inúmeras marcas representativas ampliam cada vez mais o leque de opções para cada estação. Com tantas ofertas, muitas tendências se repetem e peças parecidas são expostas como novas na coleção seguinte.

A multiplicidade na moda pode representar liberdade na forma de se vestir e de se expressar por meio das roupas. De acordo com Svendsen (2010), a ideia de que tudo é permitido na moda atual é uma falsa sensação de independência. 0 que ocorre, pelo contrário, é a multiplicação de normas, que continuam presentes e são tão impositivas quanto quando a moda era caracterizada pela uniformidade. Essa falsa sensação de liberdade ocorre justamente pela multiplicidade de estilos propostos. 
A busca pelo novo e pela identidade individual, mesmo que dentro de um grupo, faz com que coleções tenham que ser reinventadas para, no mínimo, alimentar a ilusão dos usuários de que algo novo está sendo disponibilizado. De acordo com Svendsen (2010), apesar da produção de massa, a moda atual proporciona a criação da expressão individual. E com as ofertas feitas pelo mercado, as crianças também elegem o grupo ao qual querem pertencer e com quem desejam parecer. Suas escolhas são feitas de acordo com o que querem que thes seja associado, mesmo que isso não seja feito de forma consciente.

As crianças frequentemente alimentam a fantasia de ser adulto em brincadeiras e representações, muitas vezes com o uso de peças de roupa, calçados e maquiagem de seus pais. De acordo com Navarri (2010), o ponto de partida é sempre o da imitação. Na moda infantil, o jogo da imitação é frequente e, entre os personagens de reprodução, estão o super-herói, a princesa, o míni-homem, a minimulher, o astro de rock, o personagem do desenho, entre outros.

Sendo a moda também responsável por propostas de atitude e comportamento, o século XXI experimenta algumas transformações em que não só as roupas estão sendo reinventadas, mas estão sendo reproduzidas e realocadas para um público diferente do proposto anteriormente. Isso porque as posições sociais que adultos e crianças ocupam na sociedade estão se misturando, fundindo-se em alguns aspectos, o que é facilmente observável na moda com o uso de caracteristicas infantis pelos adultos e vice-versa. De acordo com Postman (1999), falar que a infância está desaparecendo é tão verdadeiro quanto falar que a idade adulta também está, isso porque destaca a vontade de pais e filhos se parecerem fisicamente - esses limites, muitas vezes, são bastante tênues.

Segundo Apter (2004), as crianças de hoje estão crescendo mais rápido do que nunca; em contraponto, demoram muito mais tempo para se tornarem adultas, o que confirma a aproximação da idade adulta com a infância, proposta por Postman (1999). Concordando com a ideia de prolongamento da juventude, de acordo com Svendsen (2010, p. 68), "a juventude está sempre sendo esticada, de modo que, cada vez mais, se torna um estado permanente em vez de uma fase de transição".

De acordo com Pereira (2002, p.83), "no contexto contemporâneo das sociedades ocidentais, a relação entre adultos e crianças tem sido marcada por um desconforto oriundo da imprecisão dos lugares ocupados pelos indivíduos". A autora vai ao encontro de Postman (1999) ao afirmar que a linha divisória entre ser adulto ou criança está cada vez mais imperceptivel, isso porque uma das grandes contradições presentes na sociedade do século XXI está relacionada com a inversão de valores entre crianças e adultos.

Para Navarri (2010, p. 126), a vontade inconsciente dos adultos de se tornarem mais jovens, por sua atração pela "onipotência dos desejos infantis", ocasiona uma desorientação da linguagem entre ser adulto e ser criança. $\mathrm{Na}$ moda, essa confusão torna-se clara com os miniadultos, uma das tendências 
infantis mais representativas do século XXI. Os miniadultos, que podem ser explicados como resultado dessa troca de conceitos, têm suas roupas transformadas em verdadeiras armas quando "o desejo da sedução próprio às crianças as impulsiona a crescer para serem capazes de seduzir como os adultos".

Essa parecença das crianças com os adultos não é apenas caracteristica do século XXI, pois, em diversos momentos na história, as crianças foram vestidas com caracteristicas adultas. Isso vem se repetindo com o passar dos séculos, desde antes mesmo do início do que hoje entendemos como moda. Todavia, na atualidade, a falta de delimitação entre adultos e crianças se dá não só pela caracterização adulta nas vestes infantis, mas também pelo caminho contrário.

Enquanto os adultos cada vez mais mostram a sua vontade de permanecerem jovens por meio das roupas, da maquiagem e dos tratamentos estéticos, as crianças são vestidas como miniaturas deles e são cobradas para terem atitudes que não condizem com as suas idades, não só em relação à moda, mas a todo o contexto social implicado na questão da inversão de valores entre adultos e crianças. Navarri (2010, p. 129) destaca que "a infância não é mais considerada como um momento particular da vida, com seu tempo, suas preocupações, os adultos inscrevem o conjunto em um registro único para poder continuar a fazer parte dele".

A fim de ilustrar essa inversão/aproximação entre crianças e adultos na moda, podemos esquematizar de forma simples os caminhos pelos quais a moda infantil e a adulta de dividem.

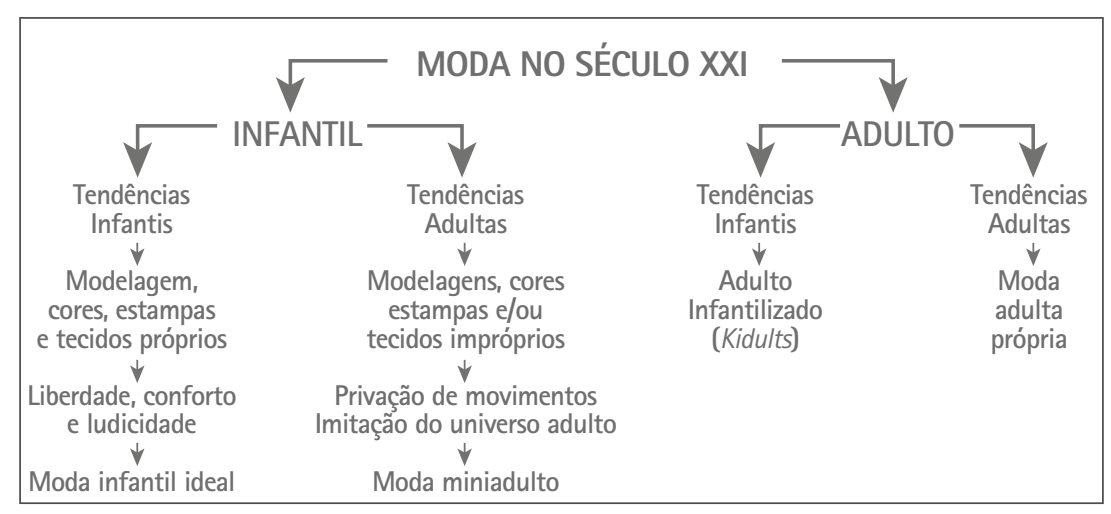

Figura 1 - Esquema de inversão de idades observado para a criação de moda do século XXI. Fonte: Elaborado por Julia Bernhard.

Nesse esquema, de forma sucinta, podem-se observar os resultados das inversões de valores nas tendências de moda. Na moda adulta, têm-se os kidults $^{5}$ como resultado das tendências infantis aplicadas às suas vestes. Na moda infantil, as tendências adultas aparecem em modelagens, cores, estampas e/ou tecidos impróprios que acabam por privar movimentos ou imitar a imagem adulta para as crianças, resultando na estética do miniadulto. Quando as tendências aplicadas aos públicos condizem com as suas idades, tem-se o resultado estético e funcional próprio para cada faixa etária. 
A inversão de valores e a aproximação entre crianças e adultos confirmam uma das mais representativas tendências da moda infantil do século XXI, a do miniadulto. Todavia, a multiplicidade vivida na atualidade, voltada para a moda infantil, abrange diversos conceitos e épocas. Assim como a moda adulta, a infantil apresenta variações em tendências e conceitos, participa de diversas tribos e absorve inúmeras identidades. Com isso, muitas tendências são apresentadas para vestir as crianças, tanto as que preservam as características do universo infantil ideal quanto as que reproduzem a roupa dos adultos em escala menor, como observado em séculos passados.

Roupas confortáveis e alegres, com modelagens apropriadas e tecidos leves, coloridos e estampados, vestem as crianças ao mesmo tempo em que peças com estruturas pesadas, modelagens ajustadas e cores austeras também estão disponiveis para fazer parte do guarda-roupa infantil. 0 século XXI apresenta-se como um grande mercado de estilos, em que as crianças ou seus pais podem escolher o que mais Ihes agradam. E assim como os adultos, as crianças acabam aderindo às inúmeras tendências de moda, assumindo diferentes papéis sociais de acordo com as situações vividas. Dessa forma, tendências que respeitam a liberdade de movimento e a ludicidade das crianças são utilizadas ao mesmo tempo em que outras reproduzem miniaturas de adultos, sendo algumas delas apresentadas neste artigo.

\section{Mini me: A moda adulta em escala reduzida para o uso infantil}

Apesar de a atualidade conhecer as necessidades e a importância do conforto, da liberdade e da fantasia nas vestes infantis, apenas o aspecto da fantasia parece ser levado em conta. Conhecida por mini me, essa tendência é uma das mais representativas do início do século XXI e caracteriza-se, principalmente, pela reprodução de roupas adultas para as crianças.

Sobre o uso de modas com referências adultas por crianças, Lurie (1999) afirma que as crianças vestidas como miniadultos podem ser vistas de forma não positiva. A criança com roupas formais de adulto pode sugerir sexualidade precoce. Navarri $(2010$, p. 126) também defende a ideia de sexualidade precoce, e, para a autora, os adultos negam a sexualidade nas crianças e, por isso, permitem que elas se vistam como suas cópias em escala reduzida, "sob o pretexto errôneo de que, para elas, o valor da sedução sexual é inexistente".

Essa antecipação da moda adulta para a infantil acaba por anular as diferenças que são necessárias entre roupas de diferentes faixas etárias. A transição das idades deixa de ser sinalizada pelo visual proposto pelo vestuário, não havendo evolução na moda que segue essa tendência.

0 fato de não haver diferenciação entre as modas adulta e infantil representa que não há transições ou avanços de uma idade para a outra e, assim, a moda torna-se fator unificador entre a infância e a idade adulta. Dessa maneira, as roupas passam a ser diferenciadas basicamente pelo tamanho e pela quantidade de tecido empregada em cada peça. 
A mini me da atualidade é a tendência que mais se assemelha com o restante das ocorrências da parecença da moda infantil com a adulta ocorrida em outros períodos históricos, como visto anteriormente. As vestes infantis em escala reduzida da adulta, como ocorria na Idade Média, voltam a aparecer na atualidade com a multiplicidade de identidades representadas por diferentes estilos.

Vender a ideia de adultização para crianças e ter a aceitabilidade dessa forma de inversão durante um período tão longo, neste início do século XXI, demonstra não apenas uma tendência de moda, mas sim mudanças no perfil da sociedade. As propagandas analisadas a seguir mostram de que forma essa tendência é evidenciada nas revistas. A primeira imagem analisada foi veiculada na revista Vogue, no ano de 2002.

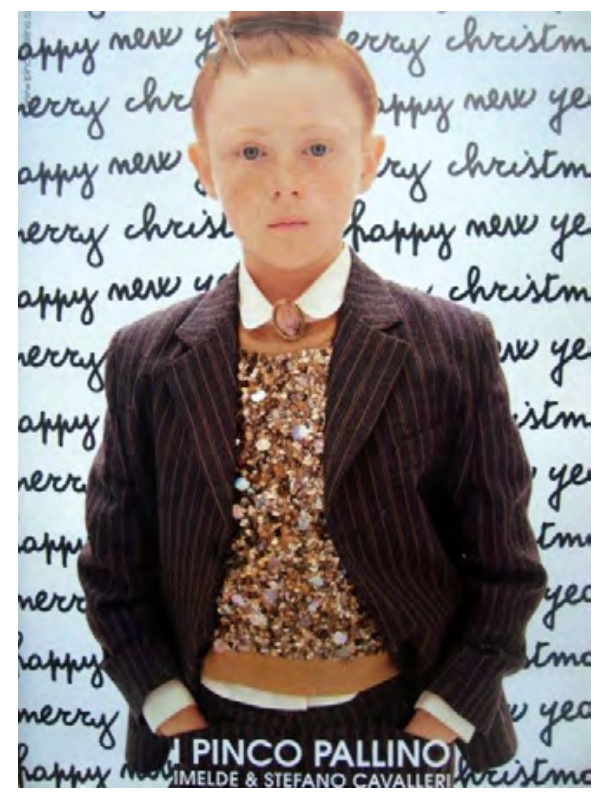

Figura 2 - Anúncio da marca I Pinco Pallino. Fonte: Vogue Bambini, 2002, n. 171.

0 anúncio corresponde a uma página no interior da revista: é constituído de cenário de fundo branco com texto linguístico merry christmas e happy new year em preto. À frente, identifica-se um modelo infantil, do sexo feminino, vestindo terninho cinza com risca de giz caramelo. Por baixo do paletó aberto, usa uma malha caramelo com decote redondo bordada com paetês dourados e, por baixo dela, uma camisa social branca de manga longa, passivel de identificação por causa da visibilidade da gola e dos punhos. Como acessório, usa broche elíptico dourado com pedra rósea disposto no centro da gola. Na base da página, sobreposta à modelo, aparece a assinatura da marca.

As cores do produto são sóbrias, com exceção do dourado: cinza, caramelo e branco. 0 cinza escuro sugere seriedade, aumentada pelo padrão risca de giz caramelo. De acordo com Sabino (2010, p. 526), embora seja usado em roupas masculinas e femininas, esse padrão "é um clássico da indumentária masculina". 0 caramelo e o dourado são associados ao ouro e, dessa forma, passam a ter relação com riqueza. Por fim, a cor branca, com significados 
contrastantes quando associada à camisa social, é relacionada à formalidade e às ações intelectuais. A iluminação do anúncio privilegia o produto, não havendo ponto específico de luz incidindo sobre determinada parte da página.

Com a variação de materiais, as texturas variam de lisas, para o terno e a camisa, a granuladas, para a aplicação de paetês. As texturas rugosas presentes na imagem são resultado da postura da modelo que se apresenta de frente para o espectador, com rosto sério, voltado para a mesma direção, e mãos nos bolsos.

A partir da análise dessa peça publicitária da I Pinco Pallino, podemos salientar as seguintes caracteristicas: seriedade, maturidade, masculinidade, casualidade, formalidade e festividade. As peças apresentadas na imagem, exceto a malha com paetês, além de serem originariamente de uso masculino, são associadas fortemente ao vestuário adulto.

0 que quebra a formalidade expressa nesse conjunto é a presença dos paetês, que aparecem em peça utilizada facilmente por mulheres adultas. Aqui, ela é associada à festividade, uma vez que se tem a informação da relação desse anúncio com as festas de fim de ano. Não há, na combinação das peças, qualquer característica que, isolada ou em conjunto, possa ser identificada como pertencente ao vestuário infantil. Pode-se classificar essa proposta de moda como miniadulto formal.

A segunda imagem analisada é de um anúncio da marca Brooksfield, conforme podemos observar a seguir.

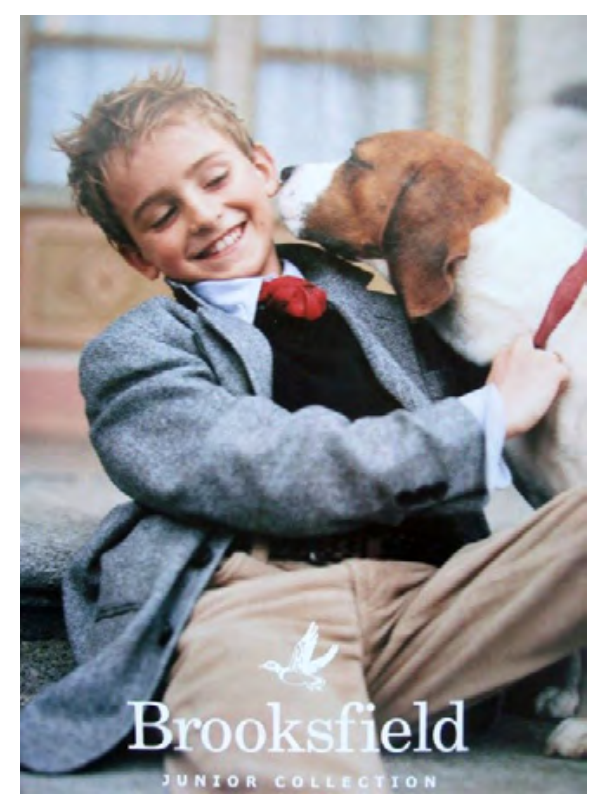

Figura 3 - Anúncio da Brooksfield. Fonte: Vogue Bambini, 2002, n. 171.

0 anúncio corresponde a uma página no interior da revista: é constituído de cenário que remete à calçada na frente de uma residência, com degraus e porta de madeira com vidro ao fundo. Identifica-se um modelo, 
do sexo masculino, sentado com um cachorro. Quanto ao produto, o menino veste camisa social manga longa azul-claro, gravata vermelha, suéter de malha preto, blazer cinza, provavelmente de lã, com a gola parcialmente levantada, e calça bege.

No produto, as cores presentes são cinza, branco, preto, vermelho e bege. Essa combinação de cores sóbrias com o vermelho é utilizada por adultos em trajes semelhantes. A iluminação privilegia o produto, não havendo foco de luz demarcado em nenhuma região específica do anúncio. A textura predominante é a rugosa, principalmente em função da postura do modelo que se encontra sentado, com o corpo reclinado para trás e para a esquerda (por causa do cachorro), está de frente para o espectador. Uma das mãos segura a coleira do cachorro e não é possivel ver a outra. As pernas estão abertas, uma abaixada e a outra dobrada, com o joelho alto, e são cortadas pelo enquadramento. 0 rosto se apresenta inclinado para a esquerda; o menino olha para baixo e sorri.

A análise desse anúncio da Brooksfield pode ser associado a dois aspectos principais: a formalidade e a casualidade. As vestes propostas para os meninos, a partir dessa publicidade, são relativas a roupas adultas correspondentes ao traje passeio.

A combinação da camisa com a gravata, o suéter, a calça clara e o blazer escuro é característica desse traje, muito associado ao uso adulto. A formalidade das modelagens é quebrada com a combinação de cores, que faz com que o traje se torne casual. Todavia, essa casualidade não é suficiente para que

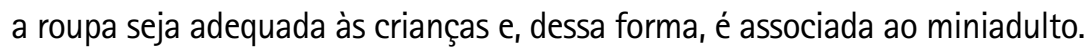

\section{A ludicidade e o conforto a favor da infância na moda}

Contrastando com a tendência mini me, a moda infantil que preserva a liberdade e a fantasia infantis também se mostra presente no século XXI. Apesar de a criança procurar a imitação como forma de identificação pela vestimenta, as modelagens, os materiais confortáveis e as combinações de cores alegres são caracteristicas demasiadamente importantes para o bem-estar infantil em relação às suas vestes.

As roupas infantis devem ser pensadas, durante o seu desenvolvimento, sobretudo, no que se refere ao conforto ao toque, na leveza e na liberdade de movimentos. 0 conforto deve ser proporcionado não só pelo tecido base da peça, mas também pelos seus acabamentos e forros. Além da comodidade, a praticidade também é muito importante, e esses dois aspectos em conjunto são normalmente associados a roupas sem muitos detalhes, babados ou camadas, embora sejam aspectos que infantilizam visualmente as crianças.

0 conforto físico proporcionado pelo uso de roupas ideais faz-se importante para o desenvolvimento infantil, inclusive para o seu sentimento de liberdade, uma vez que a criança passa grande parte do tempo fantasiando. De acordo com Radino (2003, p. 148), "é a ansiedade adulta, de adultificar a criança, que acaba forçando-a a abandonar seu desenvolvimento natural e a pular etapas". 
Novamente 0 adulto aparece antecipando o desenvolvimento das crianças. De acordo com a autora, se a criança não tem acesso à fantasia, ela não tem a chance de construir o conhecimento e passa a aceitar as informações impostas como realidades imutáveis. Estas podem ser relacionadas com as respostas dadas às perguntas não feitas, como Postman (1999) trata em relação à adultização da infância.

A moda infantil pode ser um veículo facilitador de vivências infantis, e uma das formas para conseguir isso pode estar relacionada simplesmente com a não adultização das roupas das crianças, proporcionando-lhes conforto e liberdade para a realização de suas brincadeiras. Outra forma pode ser associada à criação de roupas lúdicas, alegres e que incitem a fantasia, sempre levando-se em consideração o conforto.

Assim como a moda do miniadulto proporciona às crianças experiências da fantasia de ser adulto e ser como os seus pais, a moda infantil ideal está relacionada com a ludicidade, o respeito em ser criança, além do conforto e da liberdade para a realização de suas brincadeiras e fantasias.

A imagem abaixo mostra um anúncio no qual as crianças parecem representar o papel originalmente destinado a elas, ou seja, o de serem crianças.

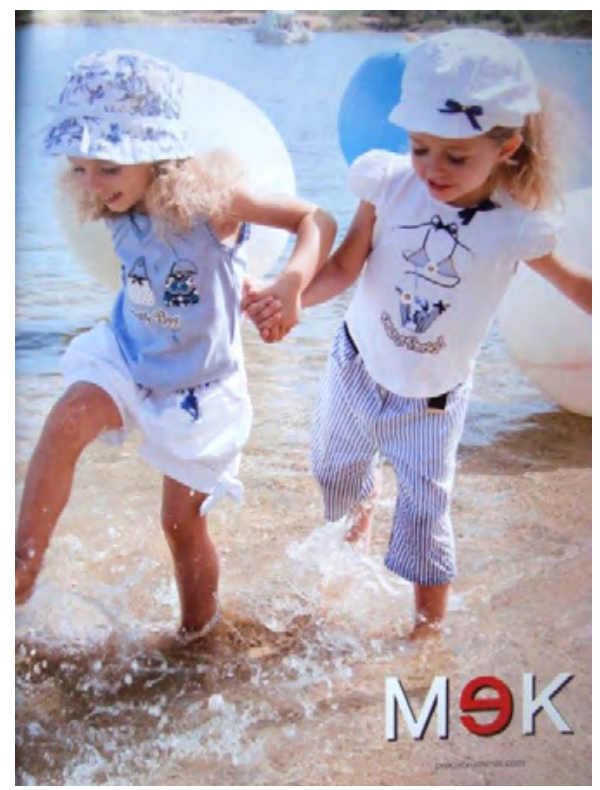

Figura 4 - Anúncio da marca MEK. Fonte: Vogue Bambini, 2008, n. 203.

0 anúncio corresponde a uma página no interior da revista: é constituído de cenário natural, de praia, predominando a água. Há uma faixa de areia na base da página e, no topo, há uma faixa de pedras, com vegetação e céu. Além da paisagem natural, identificam-se boias circulares e lancha centralizada horizontalmente na metade superior do anúncio.

0 produto é vestido por duas modelos com caracteristicas físicas e idades semelhantes que, de mãos dadas, brincam na beira da praia. A menina 
da esquerda veste short franzido nas pernas e no cós, com bolsos frontais, amarração na base das pernas e faixa de tecido estampada floral na cintura, regata azul-claro com decote e cavas adornados por bordado, decote $\mathrm{V}$ com vista interna, deixando-o menos profundo. Ao redor do decote, há três nervuras de cada lado, e no centro da blusa, há estampa de bolsinhas que só se vê parcialmente. A menina da direita veste calça listrada com comprimento na metade da panturrilha, três bolsos frontais (dois redondos e um pequeno, para moeda), fechamento por zíper e cinto azul-marinho. Veste blusinha com decote redondo e manga curta bufante com estampa frontal centralizada de um biquíni com margaridas e laço de fita aplicado no decote. As duas modelos estão descalças e usam chapéu de tecido como acessório.

As cores predominantes nos produtos são o azul, que varia do marinho ao claro, e o branco. Há pequenos detalhes em amarelo, como o centro das margaridas estampadas localizadas na blusinha da modelo da direita. Os azuis, de acordo com Valcapelli (2001), podem ter significados diferentes, dependendo da tonalidade, sendo o azul-claro ligado à calma e à tranquilidade e 0 marinho à depressão e também pode ser associado à formalidade. 0 branco, de acordo com Smith (2004), é vinculado aos seres celestiais pelo cristianismo. Essa combinação de cores na moda é muito usada para fazer referência ao estilo marinheiro, inclusive pelas crianças a partir do século XVIII. A iluminação, aparentemente natural, é superior e dá destaque a determinadas partes do produto, como é o caso da lateral da modelo da esquerda. A modelo da direita não recebe iluminação que privilegie as vistas frontal e lateral do produto, mas, de toda forma, a luz incide sobre as meninas, o que faz com que 0 produto seja observado.

No produto, texturas lisas e rugosas aparecem seja por conta de efeitos causados pelos movimentos, seja por costuras e recortes das peças. As texturas rugosas provocadas pela confecção do produto estão localizadas no decote da regata azul, nas pernas do short branco e nas mangas da blusinha branca. As demais texturas rugosas presentes no produto foram formadas por causa da posição e do movimento que as meninas faziam no momento da captura da imagem: uma caminhada descontraída, chutando ou pisando na água.

A partir da análise da peça publicitária da marca MEK, observam-se as seguintes características: conforto, leveza, ludicidade, feminilidade e casualidade. 0 conforto faz-se presente em todas as peças por conta das modelagens, soltas no corpo e com comprimentos e decotes que não restringem os movimentos das crianças, e dos tecidos empregados, aparentemente leves e de origem natural.

0 único aspecto que pode fazer menção ao vestuário adulto, nesse caso, é o decote $V$ da regata azul, cuja profundidade é reduzida pela presença de vista interna. Esse aspecto, aliado às nervuras na altura do busto, faz com que a peça, se confeccionada em tecido com transparência ou brilho, por exemplo, torne a modelagem mais apropriada ao uso adulto. Todavia, a malha, aparentemente de algodão, e as cores empregadas no tecido e nas estampas fazem com que a peça seja adequada para as crianças. 
A última imagem analisada é a da marca Tommy Hilfiger.

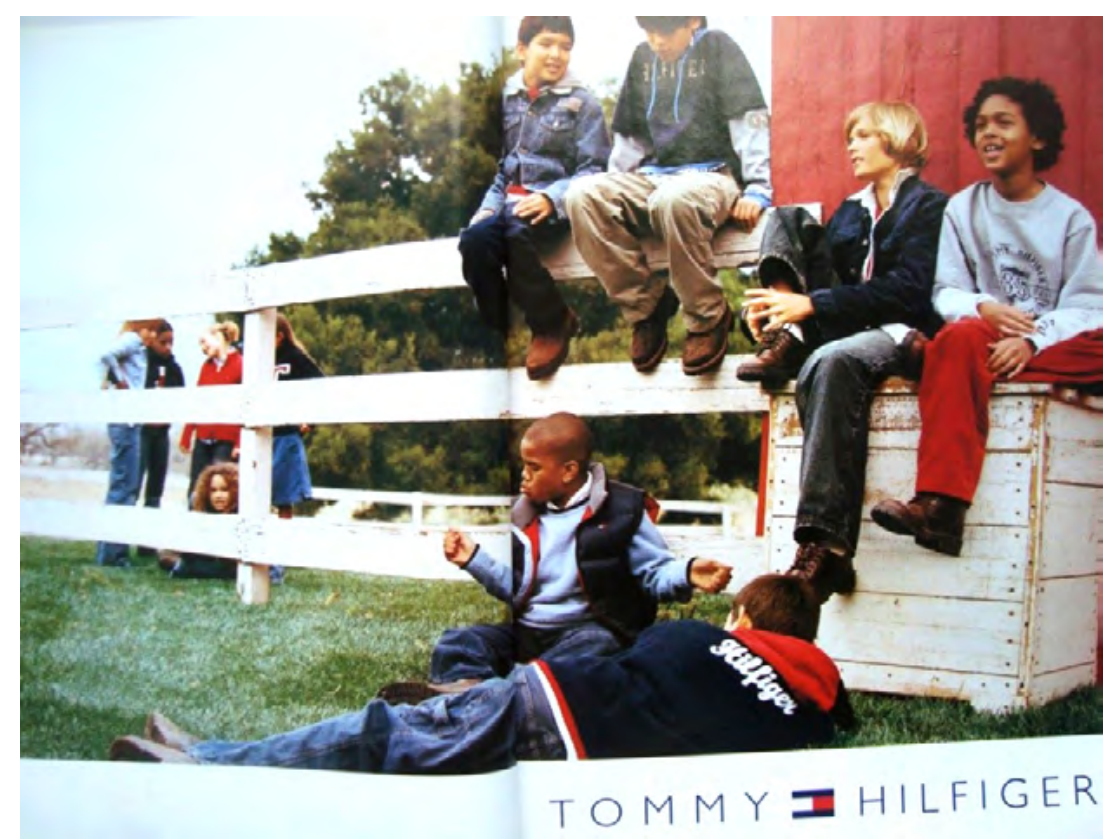

Figura 5 - Anúncio da Tommy Hilfiger. Fonte: Vogue Bambini, 2002, n. 171.

0 anúncio corresponde a duas páginas espelhadas no interior da revista: é constituído de cenário que remete a uma fazenda, com cerca alta de madeira branca horizontal, parede de mesmo material na cor vermelha (que pode ser a de um celeiro) e caixa alta de madeira branca, que pode servir para 0 armazenamento de comida para animais. No cenário, ainda se percebe a grama verde no chão, árvores com e sem folhas ao fundo e o céu em tom azul-claro acinzentado.

São identificados dois grupos de crianças. Na página da esquerda, ao fundo, cinco meninas e, na página da direita, em primeiro plano, um grupo de seis meninos. Na análise da imagem, são considerados apenas os meninos, uma vez que as meninas encontram-se atrás da cerca e sem foco e, por causa disso, muitas características da roupa se perdem.

Os seis modelos do sexo masculino parecem ter idades semelhantes. Sobre o produto, em sentido horário, do alto para baixo: o primeiro menino veste calça azul-marinho, moletom vermelho com capuz cinza e jaqueta jeans azul-escuro com fechamento por botões metálicos, bolsos frontais e aplicação de bandeira dos Estados Unidos acima do bolso direito. 0 segundo veste calça cargo cáqui, sobreposição de camiseta com moletom com capuz nas cores azul, azul-marinho, cinza e bege com estampa da marca Hilfiger na frente e o numeral 85 na lateral. 0 terceiro usa calça jeans preta, camiseta vermelha, camisa branca com a gola levantada e jaqueta jeans azul com botões metálicos. 0 quarto veste calça de sarja vermelha e moletom cinza e branco com efeito de sobreposição na manga, estampa serigrafada no centro da frente e na manga direita com os fragmentos visiveis Tommy Hilfiger 85 States. 0 
quinto menino, deitado de costas, veste calça jeans azul e jaqueta azul-marinho com capuz vermelho e barra vermelha e azul e aplicação nas costas da marca Hilfiger. 0 sexto usa calça jeans azul, camisa branca, blusa de malha azul-claro com detalhe marinho nos punhos e na gola e colete em matelassê de material sintético azul-marinho com o logotipo da marca aplicado no peito do lado direito, com o forro da gola vermelho, branco e cinza. As modelagens são predominantemente soltas no corpo e todos os meninos calçam botas em tons de marrom.

No produto, as cores predominantes são o azul, o azul-marinho, o vermeIho, o cinza, o preto, o bege e o branco. Sobre o vermelho, Valcapelli (2001) afirma ser a cor da atração e do querer ser visto e, em contraponto, o cinza é relacionado com a ausência e com a invisibilidade. 0 preto, apesar de ser ligado ao luto, é também associado à sofisticação, enquanto o branco é vinculado à riqueza e à pureza. 0 bege sugere maturidade, mas também é facilmente ligado a ambientes de interior e à natureza. As cores contrastam não só em seus tons, mas também em seus significados e interpretações, havendo, assim, equilibrio entre a euforia do vermelho e a ausência do cinza. Não há iluminação específica que direcione o olhar para determinado modelo. No produto, apesar da variação de materiais, a textura predominante é a rugosa, principalmente em função da postura dos modelos.

Observa-se que as roupas propostas nesse anúncio da Tommy Hilfiger propõem conforto, esportividade, casualidade, descontração e um pouco de formalidade. Esta última caracteristica é presente pelo uso da camisa social em duas das seis combinações propostas. Todavia, a falsa e a real sobreposição de peças, a combinação de cores, as modelagens soltas no corpo, o uso de capuzes e estampas mantêm as roupas mais caracterizadas pela casualidade, descontração e esportividade, sendo esses aspectos de extrema importância para as roupas infantis.

\section{A moda infantil atual}

A partir da análise das imagens relativas às duas grandes tendências, observa-se a multiplicidade de identidades de moda propostas para as crianças. A heterogeneidade em relação ao mesmo periodo, a homogeneidade em relação a periodos distintos comparados, a quebra dos ciclos da moda e a irracionalidade da moda são alguns aspectos que podem ser vistos com esta análise.

A heterogeneidade, caracterizada pela multiplicidade de identidades de moda, é facilmente observada quando se pensa no elevado número de tendências e propostas de estilo que coexistem na mesma estação, até mesmo nos mesmos espaços sociais. Na moda infantil, têm-se todos os perfis citados nas análises e muitos outros, tais como a criança lúdica, a transgressiva, a básica, a formal, a sensualizada e a social. Eles estão presentes na mesma revista e na mesma estação e se repetem nas próximas coleções e revistas. Assim, essa heterogeneidade se transforma em homogeneidade. Não que esta seja associada à formação de apenas um estilo, mas à permanência dos mesmos estilos por longos períodos de tempo, confirmando a perda do ciclo da moda. 
0 século XXI, a partir da confirmação obtida nas análises das imagens, não só se aproxima do século XVII, período em que o conceito de infância é considerado em sua fase inicial por alguns autores, como também à época na qual foi dado o melhor tratamento aos infantes, entre os séculos XIX e XX. Essa aproximação da atualidade com periodos tão distintos é possivel por conta da multiplicidade de estilos aos quais as crianças têm acesso e usam.

As tendências que aproximam as crianças dos adultos em relação ao vestuário podem ser ligadas ao período do surgimento do conceito de infância, quando foram reconhecidas as necessidades de conforto e liberdade das crianças. Essa ligação é possivel pelo fato de que, mesmo em poder desse conhecimento, as roupas continuavam sendo produzidas para as crianças apenas em tamanhos reduzidos, com pequenas ou nenhuma alteração, das roupas dos adultos.

Por outro lado, as tendências que preservam o conforto das crianças, sem aproximá-las dos estilos dos adultos, podem ser relacionadas com 0 período do apogeu da infância, época em que muitas transformações se deram tanto nas relações familiares quanto nas roupas infantis. Embora esse período não tenha sido linear, em razão de algumas modas periódicas não confortáveis criadas para as crianças, é o que mais se assemelha a essa tendência do século XXI.

Ainda é possivel relacionar a moda básica, aqui mencionada nas duas tendências analisadas, com o periodo de inexistência da infância. Isso porque, naquele momento, as roupas eram também parecidas para adultos e crianças, como nas roupas básicas atuais, e essa semelhança não representava prejuízos para os movimentos ou a liberdade das crianças.

Em suma, a moda infantil atual, que varia do infantil lúdico ao miniadulto formal, tem a multiplicidade de estilos como caracteristica principal. 0 fato de se ter o conhecimento sobre a infância e de, na moda, haver criações que as ligam ao mundo adulto, faz com que, no vestuário, se confirme a ideia de declínio da infância apontada por Postman (1999) e por Steinberg e Kincheloe (2001), seja em virtude das novas organizações de família, da representatividade da mulher/mãe na sociedade ou da socialização infantil precoce em função dessas mudanças, ou em função da tecnologia, do acesso à informação provinda da televisão e de anúncios publicitários como os aqui analisados. Independentemente de qual é o motivo com maior relevância, a moda infantil do século XXI é consequência dessa situação contraditória que dá às crianças acesso aos segredos dos adultos, causando a adultização.

Já a fragmentação das identidades está relacionada com a multiplicidade de ofertas de moda iniciada no século XX e intensificada na atualidade. Assim como as modas e as identidades são múltiplas para os adultos, as crianças estão submetidas à infinidade de opções de estilos que as aproxima dos adultos ou as distancia. Porém, não só a moda infantil está se aproximando da adulta 
como o contrário também é verdadeiro. A confusão entre as idades, no que se refere à representação por meio da moda, está instaurada e, com o passar do século XXI, só vem se fortificando.

A análise da moda infantil nos anúncios publicitários nos permite afirmar que os papéis sociais da infância nem sempre são condizentes com a moda proposta para as crianças e que o conhecimento das suas necessidades não Ihes assegura roupas com requisitos indispensáveis, como o conforto e a liberdade. Além disso, podemos dizer que a multiplicidade presente na moda atual e nas propostas de estilo infantil, que ligam as crianças tanto ao período de inexistência do conceito de infância quanto ao de seu surgimento, confirma a ideia da existência, na moda infantil atual, de sugestões de estilo que podem ser relacionadas a diferentes representações sociais da infância em períodos históricos distintos.

Recebido em: 28-03-2017

Aprovado em: 26-05-2017 


\section{NOTAS}

${ }^{1}$ Foco de análise deste artigo, as crianças são estudadas com apoio classificatório do Estatuto da Criança e do Adolescente - ECA (1990, art. $2^{\circ}$ ), em que "considera-se criança, para os efeitos desta Lei, a pessoa até doze anos de idade incompletos".

${ }^{2}$ A revista Vogue Bambini é a edição italiana da revista Vogue que se destina à moda infantil. A revista Vogue foi criada no fim do século XIX, em Nova York, com o objetivo de atender as mulheres da alta sociedade. No início do século XX, a revista "teve seu conteúdo reformulado para torná-la mais atraente e transformou a moda em 'objeto de desejo' e 'sonho de consumo' para as mulheres". Nas primeiras décadas dos anos 1900, a revista tomou proporções internacionais, sendo criadas a Vogue britânica, a francesa, a espanhola, a australiana e a alemã. A Voque Bambini é dirigida às classes média alta e alta e ao público com interesse em moda infantil. Apesar de apresentar tendências de moda e publicidades de marcas infantis, a revista não é destinada para as crianças. A linguagem é adulta e a diagramação se assemelha às edições de moda adulta. A periodicidade é bimestral. No Brasil, a correspondente é a Vogue Kids, e esta não é uma edição independente, mas um complemento da revista Vogue (adulta), e tem sua periodicidade reduzida a dois volumes por ano, relativos ao outono/inverno e à primavera/verão (MUNDO DAS MARCAS, 2011).

${ }^{3}$ Segundo o Instituto Alana, as crianças brasileiras lideram o ranking no número de horas assistidas de televisão por dia. 0 lbope de 2011 contabilizou que cada criança passa mais de cinco horas por dia em frente à televisão (INSTITUTO ALANA, 2012). Atualmente, podemos afirmar que, à televisão e à publicidade, foi adicionado um terceiro elemento tanto ou mais prejudicial para as crianças: o acesso pouco controlado à internet, entretanto, essa questão não será tratada neste artigo.

${ }^{4}$ Tendências aqui estão relacionadas tanto com as formas e materiais das roupas, definidas em estudos sobre 0 consumo, quanto com os conceitos empregados pelos designers para a criação de determinada coleção.

${ }^{5} 0$ termo kidults, união das palavras kidse adults, remete aos adultos que foram crianças nos anos 1980 e que se caracterizam pelo uso de referências infantis em suas roupas e/ou acessórios, como personagens que fizeram parte de sua infância (GLOSSÁRIO DE MODA USEFASHION, 2012).

\section{REFERÊNCIAS}

APTER, Terri. 0 mito da maturidade: o que os adolescentes precisam para se tornarem adultos. Rio de Janeiro: Rocco, 2004.

ARIĖS, Philippe. História social da infância e da família. 2. ed. Rio de Janeiro: LTC Editora S.A., 1981.

BARBOSA, Rita Claudia Aguiar; QUEDES, Walkiria. Vestuário e infância: entre a adequação e as determinações sociais. Universidad de Palermo. Buenos Aires, 2007.

HEYWOOD, Colin. Uma história da infância: da Idade Média à época contemporânea no Ocidente. Porto Alegre: Artmed, 2004.

JOLY, Martine. Introdução à análise da imagem. Campinas: Papirus, 1996.

KERN, Mônica Tonding: SCHEMES, Claudia; ARAUJO, Denise Castilhos de. A moda infantil no século XX: representações imagéticas na Revista do Globo (1929-1967). In: Diálogos, v.14, n. 2, Maringá, 2010.

LURIE, Alison. A linguagem das roupas. Rio de Janeiro: Rocco, 1997.

MARSHALL, Noreen. Dictionary of children's clothes: 1700 to present. Londres: VEtA Publishing, 2008.

NAVARRI, Pascale. Moda e inconsciente: olhar de uma psicanalista. São Paulo: Editora Senac São Paulo, 2010.

OLIVEIRA, Cristiane Madanêlo de. Brincando de ser adulto. In: Revista Eletrônica de Instituto de Humanidades. V. 6, n. XXI, Rio de Janeiro, abr/jun. 2007.

PEREIRA, Rita Marisa Ribes. Infância, televisão e publicidade: uma metodologia de pesquisa em construção. In: Cadernos de Pesquisa, n. 115. Rio de Janeiro, 2002, p. 83. Disponivel em: <http://www. scielo.br/pdf/cp/n116/14400.pdfs. Acesso em: 20 mar. 2011.

POSTMAN, Neil. O desaparecimento da infância. Rio de Janeiro: Graphia, 1999.

RADINO, Glória. Contos de fadas e realidade psíquica: a importância da fantasia no desenvolvimento. São Paulo: Casa do Psicólogo, 2003.

SABINO, Marco. Dicionário da moda. Rio de Janeiro: Elsevier, 2007.

SMITH, Nancy MacDonell. Pretinho básico: a verdadeira história dos 10 favoritos da moda. São Paulo: Planeta do Brasil, 2004.

STEINBERG, Shirley R.; KINCHELOE, Joe L Cultura infantil: a construção corporativa da infância. Rio de Janeiro: Civilização Brasileira, 2001.

SVENDSEN, Lars. Moda: uma filosofia. Rio de Janeiro, RJ: Zahar, 2010.

VALCAPELLI. As cores e suas funções: na empresa, no lar, na roupa, na personalidade e na saúde. São Paulo: Roka, 2001. 